\title{
Phenolic Resin-MWNT Nanocomposites Prepared through an in situ Polymerization Method
}

\author{
By Jian CUI, Yehai YAN, ${ }^{*}$ Jiwen LIU, and Qiye WU
}

\begin{abstract}
A simple but effective in situ polymerization method has been developed to prepare phenolic resin-based nanocomposites with pristine or carboxylated multi-walled carbon nanotubes (MWNTs) as fillers. As revealed by scanning electron microscopy, the nanotubes are well-dispersed in and strongly adhered to the phenolic resin. The resultant nanocomposites have thus obtained the improved thermostabilities. As compared to pristine MWNT-filled nanocomposite, the carboxylated MWNT-filled one has shown more improved thermostability, resulting from the higher dispersion quality of functionalized nanotubes. The related mechanisms have been analyzed qualitatively. To achieve the similar effects, however, more mixing energy should be deposited on the melt mixture in the melt-mixing process. These indicate that phenolic resin-MWNT nanocomposites with high performance may be realized by adoption of pertinent preparation method and moderate functionalized nanotubes.
\end{abstract}

KEY WORDS: Phenolic Resin / MWNT / In situ Polymerization / Nanocomposite / Dispersion Behavior / Thermal Properties /

Due to their excellent mechanical property and high aspect ratio, carbon nanotubes (CNTs) are increasingly considered to be unique reinforcement fillers for making polymer-based nanocomposites. ${ }^{1-6}$ In order to achieve strength enhancement as high as possible, homogeneous dispersion of CNTs and strong interaction between CNT and surrounding matrix are generally required. ${ }^{7}$ However, the pristine nanotubes are usually bundled due to strong van de Waals interactions, thus making their dispersibility in most of polymer matrices rather poor. Otherwise, intrinsically smooth surface and chemical inertness of the nanotubes lead to their weak adhesion to polymer matrix. As a result, the nanocomposites based on simple polymer-pristine nanotube blends prepared by highspeed mixing and/or ultrasonication have shown limited strength enhancement as compared with conventional composites, and their mechanical properties are noticeably below the highly anticipated potential. ${ }^{7-9}$ To resolve these problems, there is growing research effort in understanding the interface between CNT and matrix. Functionalization of CNTs, which permits directly tailoring of the chemical and physical properties of nanotubes according to their specific applications, is envisaged as an ideal cut-in point and has therefore been extensively investigated. ${ }^{10-15}$ Strength enhancement of the functionalized nanotube-filled nanocomposites was generally achieved. However, these functionalization techniques more or less rely on wet chemistry. Toxicity of chemicals and damage to nanotubes are issues which must be addressed. Comparatively, it may be easier and more direct as well as environment friendly for a given polymer matrix to prepare its nanocomposites by adopting a pertinent preparation method. At least, as having been proven, it is feasible for certain polymer matrix. ${ }^{8,16-20}$ In this work, taking phenolic resin as a matrix example, we have also addressed this issue.
As is well-known, phenolic resin is the first industrialized synthetic resin. ${ }^{21}$ Currently, it still has a wide range of important applications, e.g., as matrix resin for uses in nanocomposites, ${ }^{22,23}$ due to its outstanding characteristics such as flame-resisting, low smoke, and high retention rate of mechanical properties under high temperature. ${ }^{24}$ However, while various polymers have been comprehensively investigated as matrices to prepare the CNT-filled nanocomposites, little attention was paid to the relevant research on phenolic resin. In the limited literatures, pristine CNTs, except one case where toluene-2,4-diisocyanate (TDI)-functionalized MWNTs were used for preparation of the polybenzoxazine (a new class of ring-opening phenolic resin) nanocomposite, ${ }^{25}$ were directly mixed with phenolic resin to prepare the nanocomposites. ${ }^{26-28}$ It is not surprising that the improvement of mechanical properties is very low even if the resultant nanocomposite has a rather high load of nanotubes. Therefore, there is still a lot of work to be done for achievement of the high performance phenolic resin-MWNT nanocomposites.

As one of attempts, in situ polymerization method, which has been demonstrated to be a successful solution for preparation of many thermoplastics nanocomposites, ${ }^{16,29,30}$ was extended to prepare the phenolic resin-MWNT nanocomposites in this work. As a control experiment, the nanocomposite was also prepared through melt-mixing method. Dispersion behavior of the nanotubes was explored using scanning electron microscopy (SEM). Thermal properties of the resultant nanocomposites were investigated through thermogravimetry (TG) and differential scanning calorimetry (DSC). Considering that phenolic resin was synthesized through an acidic catalyst, carboxylated MWNT that has the potential to catalyze the resin synthesis on the nanotube surface was also employed in this work.

Key Laboratory of Rubber-plastics (QUST), Ministry of Education; College of Polymer Science \& Engineering, Qingdao University of Science and Technology, Box 73, Qingdao 266042, China

*To whom correspondence should be addressed (Tel: +86-532-8402-3847, Fax: +86-532-8869-2566, E-mail: yhyan@qust.edu.cn). 


\section{EXPERIMENTAL}

\section{Materials}

MWNTs were prepared by a chemical vapor deposition (CVD) process and generously provided by Chengdu Organic Chemicals Co. Ltd. (Chengdu, China). According to information provided by the supplier, as-received nanotubes have the average diameter of 10-20 $\mathrm{nm}$ and length of 10-30 $\mu \mathrm{m}$ (http:// www.timesnano.com/info/M1203.html). Phenol, formaldehyde (37 wt. \% aqueous solution), oxalic acid, urotropin, $\mathrm{HNO}_{3}$ (70\%), and $\mathrm{H}_{2} \mathrm{SO}_{4}(98 \%)$ were purchased from commercial suppliers (China) and used as-received.

\section{Carboxylation of MWNTs}

Carboxylation of MWNTs was carried out using the previously reported method. ${ }^{31}$ In brief, around 1 gram MWNTs were suspended in $500 \mathrm{~mL} \mathrm{3:1} \mathrm{(volume)} \mathrm{H}_{2} \mathrm{SO}_{4} / \mathrm{HNO}_{3}$ solution with ultrasonication in water bath for $10 \mathrm{~min}$. The mixture was then refluxed for $3 \mathrm{~h}$. After cooling, the mixture was diluted with deionized (DI) water and filtered over a $0.2 \mu \mathrm{m}$ polycarbnate (PC) membrane (Millipore Corp). The collected solid was rinsed thoroughly with DI water. Carboxylated MWNTs were finally obtained by drying the solid under the conditions of $90^{\circ} \mathrm{C}, 30 \mathrm{mT}$ Torr, and $4 \mathrm{~h}$.

\section{Preparation of Phenolic Resin-MWNT Nanocomposites} Melt-mixing Nanocomposite (MMN). Phenol, formaldehyde, and oxalic acid with a mole ratio of 1:0.9:0.0045 were put into a $500 \mathrm{~mL}$ three-necked flask equipped with a water jacketed condenser and a mechanical agitator. The mixture was then heated to $95^{\circ} \mathrm{C}$. After appearance of the cloud point, the reaction system was heated for one more hour. With standing for $30 \mathrm{~min}$, clear liquid from the upper layer was decanted and the deposit at the bottom was washed repeatedly with copious amount of $60^{\circ} \mathrm{C}$ DI water to get rid of the catalyst and free phenols. The deposit was finally taken to dryness on a rotary evaporator. ${ }^{1} \mathrm{H}$ NMR ( $d$-DMSO): $\delta=9.38-9.10(\mathrm{OH}), 7.16-$ 6.67 (phenyl H), 3.84-3.60 $\left(\mathrm{CH}_{2}\right)$ ppm. FT-IR (KBr): $v=3310$ (OH), 3010 (phenyl), 2850, $2910\left(\mathrm{CH}_{2}\right), 1602,1508,1438$, 815, 750 (substituted benzene ring), 1222, 1166, $1098(\mathrm{C}-\mathrm{OH})$ $\mathrm{cm}^{-1}$. The obtained phenolic resin has a GPC (gel permeation chromatography) number-average molecular weight $\left(\bar{M}_{\mathrm{n}}\right)$ of 550 with a polydispersity index $\left(\bar{M}_{\mathrm{w}} / \bar{M}_{\mathrm{n}}\right)$ of 2.82 . For meltmixing with MWNTs, the phenolic resin was first melted at $90{ }^{\circ} \mathrm{C}$. Calculated amount of MWNTs (1.0 wt. \% of the resin) were then added. After being strongly stirred for $30 \mathrm{~min}$, the compound was immediately discharged. By using a HAAKE torque rheometer (Rhedord 90), the compound and urotropin ( $7.5 \mathrm{wt} . \%$ of the resin) were kneaded at $75^{\circ} \mathrm{C}$ for $30 \mathrm{~min}$ with a $50 \mathrm{rpm}$ screw speed. Finally, the nanocomposite $\mathrm{MMN}$ was obtained by crosslinking the kneaded mixture at $110^{\circ} \mathrm{C} / 2 \mathrm{~h}$, $130{ }^{\circ} \mathrm{C} / 4 \mathrm{~h}$, and $180^{\circ} \mathrm{C} / 1 \mathrm{~h}$ under the pressure of $8 \mathrm{MPa}$.

In situ Polymerization Nanocomposite (PN). MWNTs or carboxylated MWNTs were dispersed in aqueous formaldehyde solution. After ultrasonication in water bath for $30 \mathrm{~min}$, phenol and oxalic acid (phenol:formaldehyde:oxalic acid = 1:0.9:0.0045, mole ratio) were added into the mixture under continuous stirring. Then the reaction was carried out at $95^{\circ} \mathrm{C}$. After appearance of the cloud point, the mixture was reacted for another $1.5 \mathrm{~h}$. Other processes are the same as those in MMN preparation except the kneading time shortened from 30 to $15 \mathrm{~min}$. The nanotube contents in PNs were estimated, according to the usage of nanotubes and corresponding PN weight, to be 0.92 and $0.95 \mathrm{wt} \%$ for MWNT-PN and Carboxylated MWNT-PN respectively. The phenolic resin extracted by acetone from newly synthesized compound shows similar NMR and FT-IR characteristics to above-mentioned resin and its $\bar{M}_{\mathrm{n}}$ and $\bar{M}_{\mathrm{w}} / \bar{M}_{\mathrm{n}}$ were measured to be 575 and 2.90 , respectively.

\section{Characterization}

FT-IR spectra were recorded on a Nicolet Impact 410 spectrophotometer. The samples were prepared from $\sim 0.2 \mathrm{mg}$ phenolic resin or its nanocomposites per gram $\mathrm{KBr}$ with the pressure of 2 tons per $\mathrm{cm}^{2}$ for $2 \mathrm{~min} .{ }^{1} \mathrm{H}$ NMR spectrum was recorded on a Bruker Avariance $500(500 \mathrm{MHz})$ instrument. GPC measurements were carried out using a Waters1515 GPC apparatus equipped with Waters Styragel HT2 column. 0.3 wt. \% phenolic resin solution in THF was used, and the elution was performed at $20^{\circ} \mathrm{C}$ with a flow rate of $1.0 \mathrm{~mL} \cdot \mathrm{min}^{-1}$ using THF as eluent. Roman spectra were obtained on a Renishaw 1000 spectrometer equipped with $633 \mathrm{~nm} \mathrm{HeNe}$ laser excitation source. TG and DSC analyses were performed on a TG 209-F1 instrument and a DSC-204F1 instrument (Netsch, Germany), respectively, under nitrogen atmosphere with a $15^{\circ} \mathrm{C} / \mathrm{min}$ heating rate. For SEM observation, the fractured surfaces of samples were coated with platinum and examined using a Jeol JSM-6340F microscope. To prepare the TEM samples, a small amount of nanotubes were dispersed by ultrasonication in ethanol and then a drop of the dispersion was immediately placed on a copper grid $(3.00 \mathrm{~mm}, 200 \mathrm{mesh})$ coated with polyvinyl alcohol film. After air-drying, the samples were observed using TEM Jeol JEM 2000EX with an accelerating voltage of $160 \mathrm{kV}$.

\section{RESULTS AND DISCUSSION}

\section{Nanotube Fillers}

Both pristine and moderately acid-treated (carboxylated) MWNTs were used as fillers. Typical SEM and TEM micrographs shown in Figure 1 reveal that the metallic and amorphous impurities appeared as nanoparticles in pristine nanotubes (Figure 1a and 1c) have been effectively removed during the acid treatment (Figure $1 \mathrm{~b}$ and $1 \mathrm{~d}$ ), but no visible chopping effect happens to the acid-treated nanotubes. In addition, it is also noted that both kinds of MWNTs exist mostly as individuals but in entangled states. On basis of TEM measurement, the diameters of pristine and acid-treated nanotubes were determined to be $17 \pm 6 \mathrm{~nm}$ and $15 \pm 8 \mathrm{~nm}$, respectively, which are basically consistent with the dimension provided by the supplier. Each datum reported here is averaged 

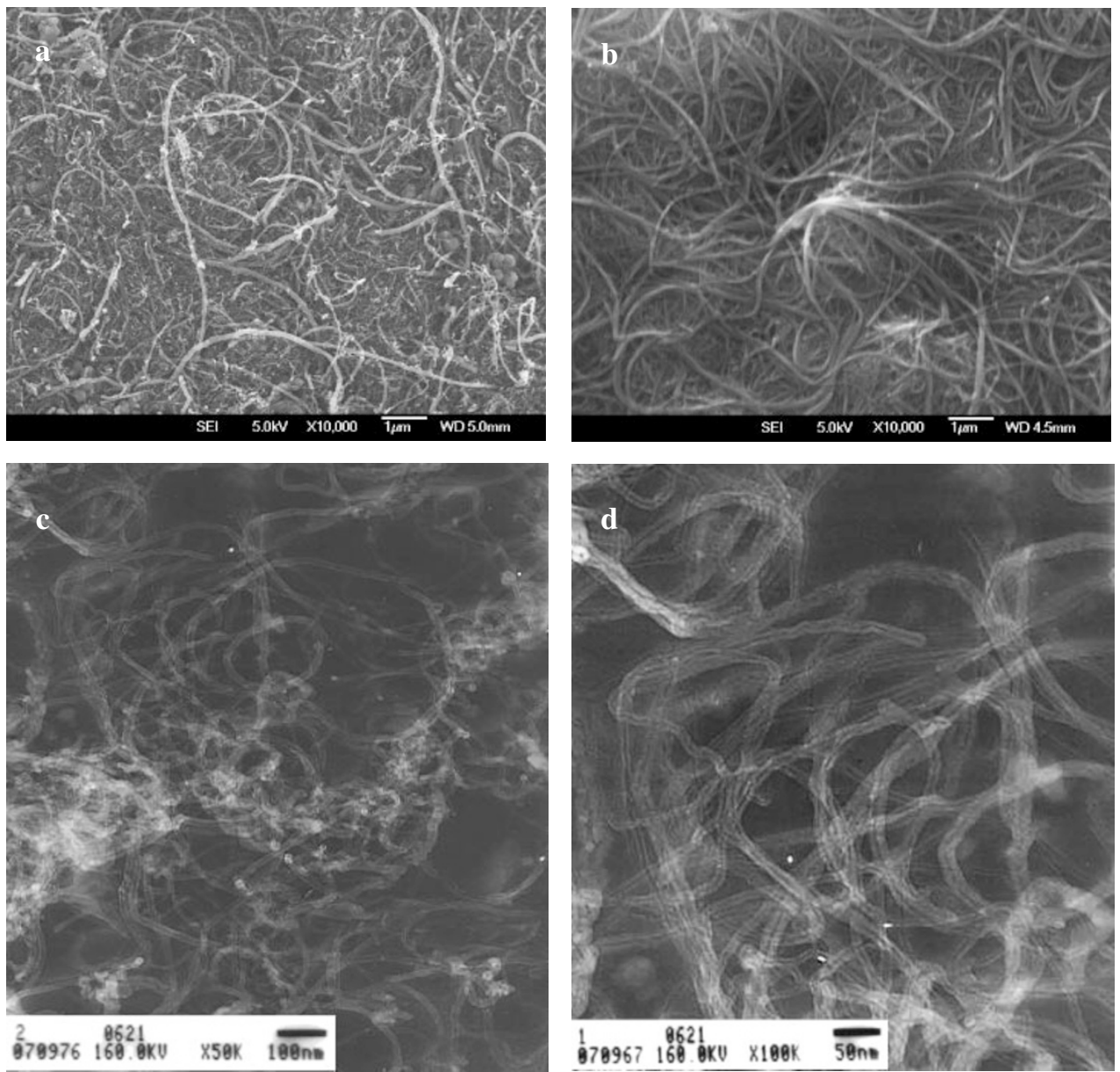

Figure 1. Typical SEM micrographs of pristine (a) and carboxylated (b) MWNTs and TEM micrographs of pristine (c) and carboxylated (d) MWNTs.

using at least twenty measurements over five micrographs taken at different locations on the sample surface.

FT-IR analyses (Figure 2a) suggest that the carboxylic acid groups have been successfully introduced into the acid-treated nanotubes, indicated by a new peak centered at $1731 \mathrm{~cm}^{-1}$ with respect to that of pristine sample. The surface structure changes of nanotubes were detected by Raman spectra (Figure 2b). The intensity ratio of disorder peak $\left(\sim 1350 \mathrm{~cm}^{-1}\right)$ to tangential peak $\left(\sim 1590 \mathrm{~cm}^{-1}\right)$ increases from 0.11 of pristine sample to 0.28 of carboxylated one. This increase has also been noticed on other acid-treated nanotubes and is usually attributed to the covalent functionalization of nanotubes. ${ }^{32,33}$ Another prominent feature in the Raman spectra is the second disorder band at $\sim 2690 \mathrm{~cm}^{-1}$, which is deemed as an intrinsic feature of the two-dimensional grapheme lattice. ${ }^{34,35}$ After acid treatment, this Raman nature doesn't change. The crystalline spectra featuring with sharp second disorder peak is still observed, indicating the slight carboxylation.

\section{Chemical Structures of Nanocomposites}

Chemical structures of nanocomposites were analyzed using FT-IR. The spectrum of Carboxylated MWNT-PN is shown in Figure 3. For comparison, the spectra of neat phenolic resin and phenolic resin/carboxylated MWNT mixture are also included in Figure 3. The FT-IR data suggest that once the nanotubes are incorporated the phenolic hydroxyl band shifts from $3310 \mathrm{~cm}^{-1}$ in neat resin to $3410 \mathrm{~cm}^{-1}$ in mixture and nanocomposite. This shift may be attributed to the destruction of intermolecular hydrogen bonds between phenolic hydroxyl groups and thus resulting in the phenol-formaldehyde structures existing dominantly as free and/or dimeric forms. In addition, relative to neat resin and mixture, the intensity of methylene band (2910 and $\left.2850 \mathrm{~cm}^{-1}\right)$ of Carboxylated MWNT-PN increases. This is due to the methylene contribution of urotropin which was used as the crosslinking agent of phenolic resin in this work. Within the limitation of instrument resolution, other characteristic bands of phenolic resin such as phenyl stretching $\left(3010 \mathrm{~cm}^{-1}\right)$, substituted benzene ring stretching $\left(1602,1508,1438,815,750 \mathrm{~cm}^{-1}\right)$, and $\mathrm{C}-\mathrm{OH}$ stretching $\left(1222,1166,1098 \mathrm{~cm}^{-1}\right)$ do not show any change after the nanotube incorporation. Such chemical structure changes are also observed in MWNT-PN and MMN nanocomposites.

\section{Dispersion Behavior}

Figure 4 shows the typical SEM micrographs of crosslinked phenolic resin and nanocomposites of MMN, MWNT-PN, and Carboxylated MWNT-PN. On the whole, the features on 

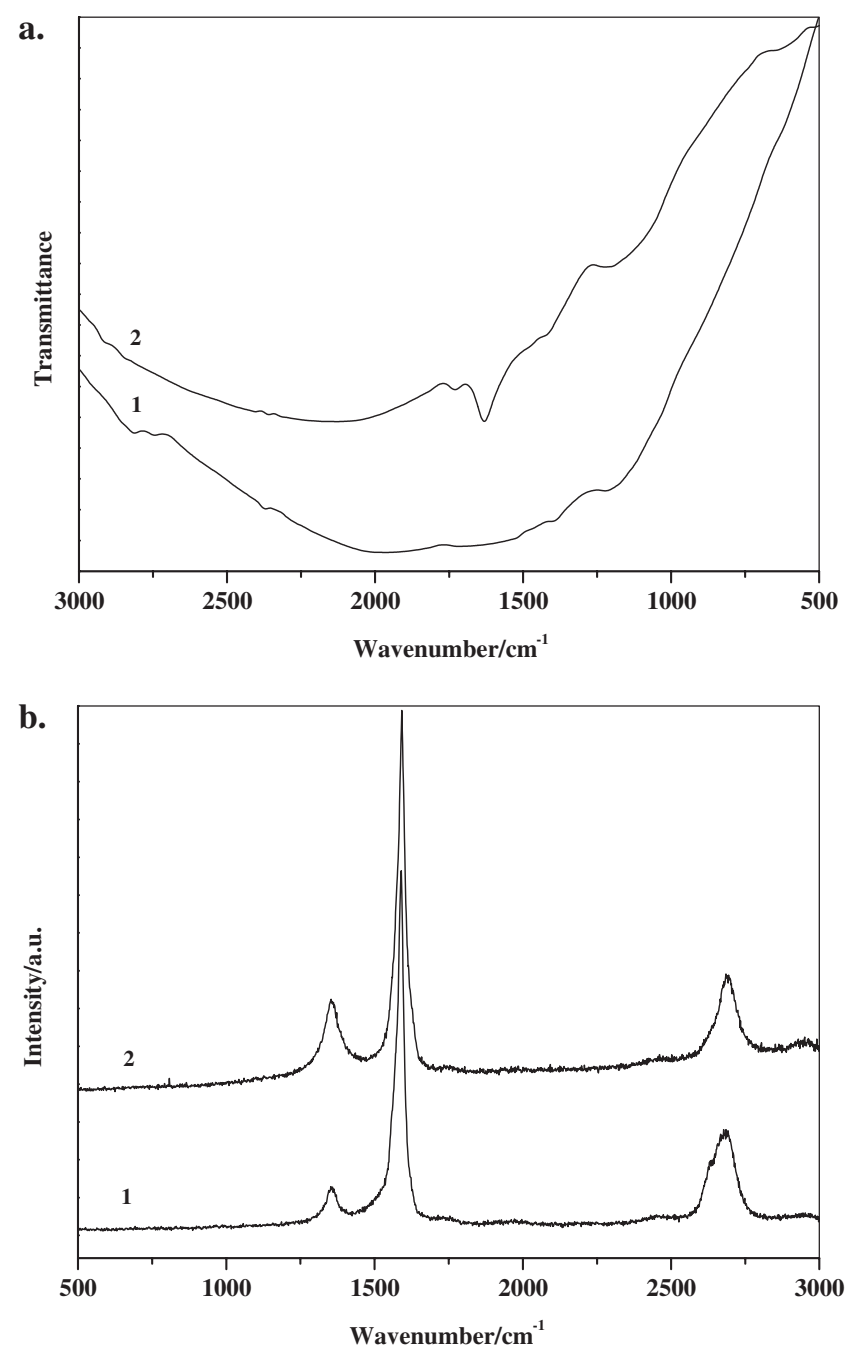

Figure 2. FT-IR (a) and Raman spectra (b) of pristine $\mathbf{1}$ and carboxylated 2 MWNTs.

fractured surface of crosslinked phenolic resin are quite smooth (Figure 4a), while the nanotubes result in crack pinning effects and formation of much rougher surface structures (Figure 4b$4 d)$. The difference in the surface roughness suggests different fracture pathways. The fracture of neat resin is in a brittle nature but that of nanocomposites in a ductile nature. Deep observation reveals that the dispersion quality of pristine nanotubes in MMN is very poor and larger nanotube agglomerates are generally observed (Figure 4b). This indicates that much more mixing energy should be deposited on the melt mixture in order to get a nanocomposite with welldispersed nanotubes. By comparison with melt-mixing processing, however, the in situ polymerization method endows the PNs with fairly high dispersion quality (Figure 4c and 4d). In this processing, a 30 min ultrasonication pretreatment, which has been widely used for nanotube dispersion in solvents, is believed to effectively disperse nanotubes into the aqueous reaction system. The subsequent strong mechanical stirring and ever-increasing viscosity of the mixture with the reaction

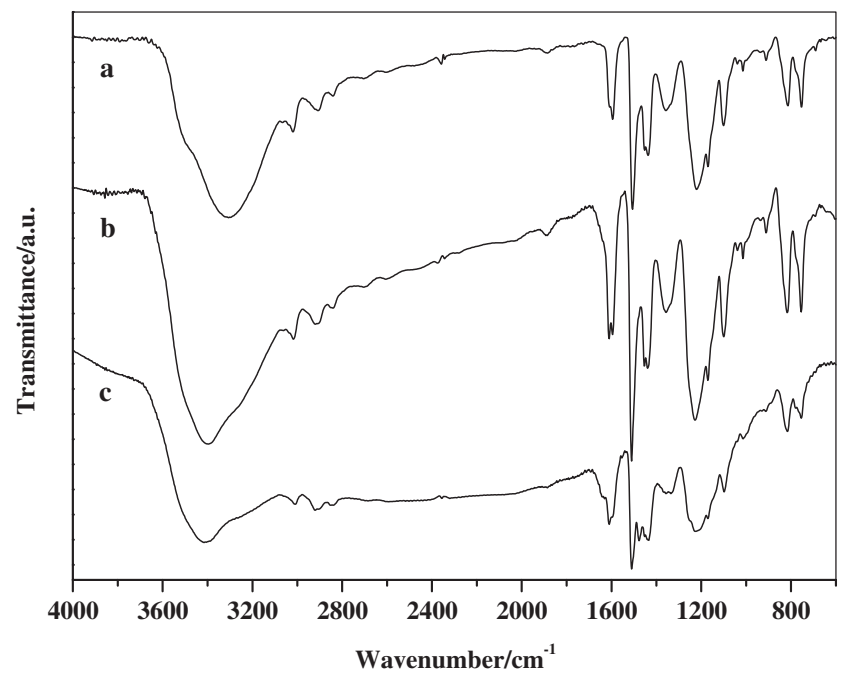

Figure 3. FT-IR spectra of phenolic resin (a), phenolic resin/carboxylated MWNT mixture (b), and Carboxylated MWNT-PN (c).

progress ensure the dispersed nanotube stable and no reagglomerated.

Upon further comparison of Figure $4 c$ with $4 d$, it is discernable that carboxylated MWNT has a higher dispersion quality in the matrix. The dispersibility improvement should be attributed to the ameliorative wettability of nanotubes, resulting from the introduced carboxylic acid groups. In addition, these carboxylic acid groups may also catalyze the synthesis of phenol-formaldehyde molecules on the nanotube surface, enhancing the matrix-nanotube adhesion. Actually, in our SEM samples, there is no observation of pulling out of embedded nanotubes from the matrix. Also, no separation of the nanotube from the matrix is noticed even if the magnification reaches to 200,000 (Inset of Figure 4d). However, as a substantial side-proof of phenol-formaldehyde molecules covering on the nanotube surface, some charging effects and noticeable distortion of the nanotube structures are typically detected during the high magnification observation.

In order to acquire structural details of the nanocomposite bulk, additional FE-SEM measurement was performed on partially cured Carboxylated MWNT-PN. At first, the composite filled with $0.95 \mathrm{wt} \% \%$ nanotubes was cured at $110^{\circ} \mathrm{C}$ for $30 \mathrm{~min}$. Then, the partially cured sample was gently immersed into acetone for $5 \mathrm{~min}$ to etch away the surface resin. The SEM observation (Figure 5) suggests that the nanotubes are well dispersed in the matrix resin and form a three-dimensional network over the etched surface. Such structural feature is usually believed to facilitate the load and/or charge transfer and thus highly expected by enhanced and conductive nanocomposites. Moreover, it is also observed that, in the nanocomposite, most of nanotubes exist in a stretched state rather than an entangled one as they exist in bulk nanotube material. Undoubtedly, the stretched nanotubes may provide the nanocomposite with more effective load bearing. 

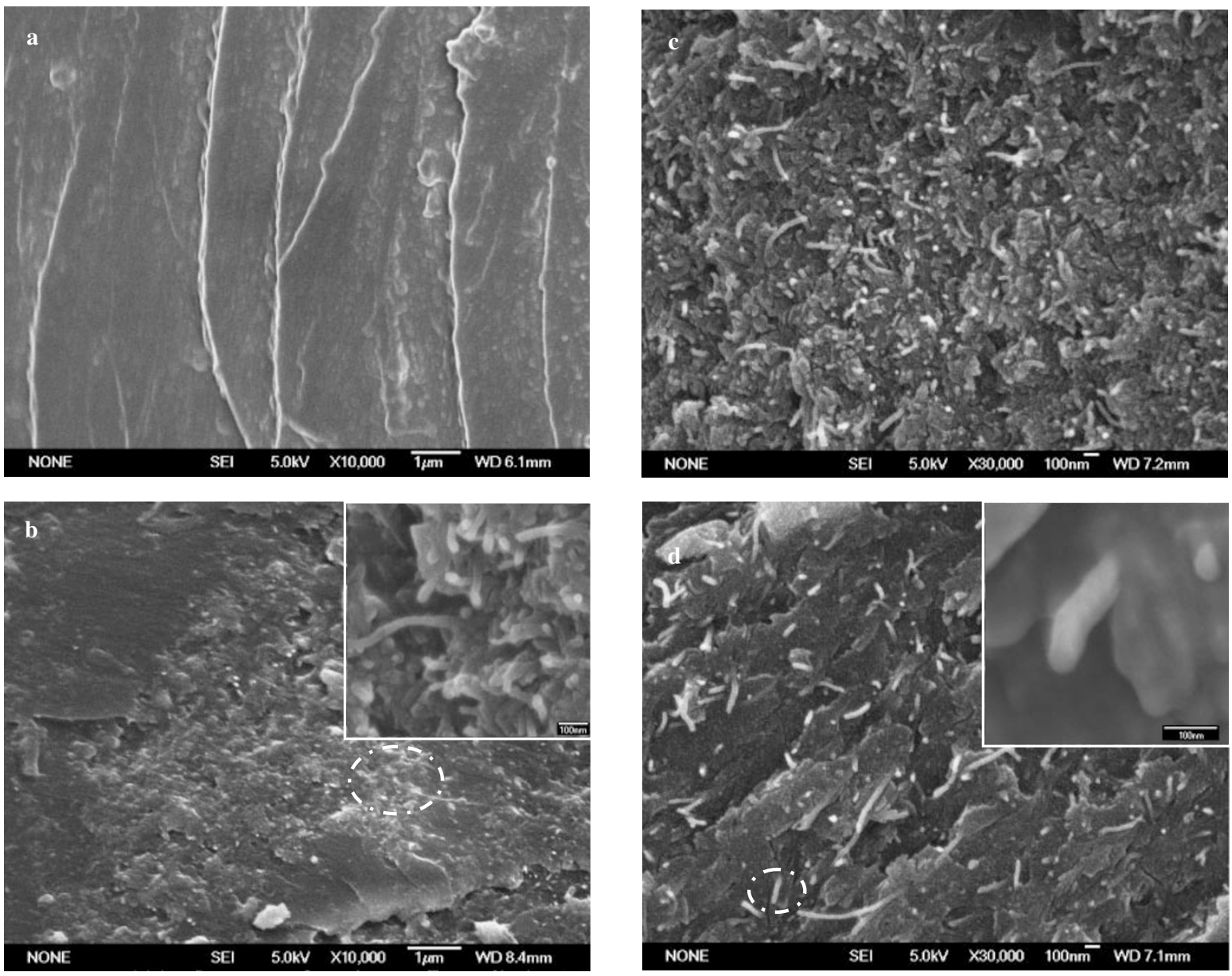

Figure 4. SEM micrographs of crosslinked phenolic resin (a) and nanocomposites of MMN (b), MWNT-PN (c), and Carboxylated MWNT-PN (d). Inset is the large magnification image of circled area; the scale bar is $100 \mathrm{~nm}$.

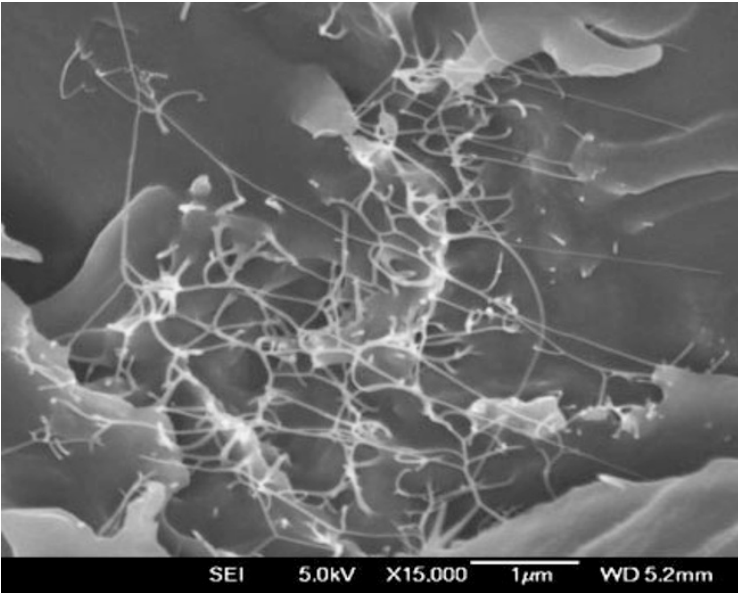

Figure 5. SEM micrograph of partially cured Carboxylated MWN-PN with its surface resin etched away by acetone.

\section{Thermal Properties}

The effect of nanotubes on the thermostability of phenolic resin was explored using TGA. Figure 6 shows that both crosslinked phenolic resin and nanocomposites have similar thermolysis behavior, featuring with three thermolytic temperature zones. The zone of $200-280^{\circ} \mathrm{C}$ is believed from the thermal decomposition of free molecules and/or imperfectly crosslinked components. The $310-430$ and $490-590^{\circ} \mathrm{C}$ zones are attributed to the decomposition of crosslinked components. In the zone of $310-430{ }^{\circ} \mathrm{C}$, all samples show the fastest rate of weight loss with the peak temperature at 385, 379, 389, and $388^{\circ} \mathrm{C}$ for crosslinked phenolic resin, MMN, MWNT-PN and Carboxylated MWNT-PN, respectively. This indicates that PNs have obtained some improvement of thermostability. The degraded thermostability of MMN is perhaps due to the nanotube agglomeration.

The residual weight, i.e., char yield, is an important performance index for phenolic resin and its composites, in particular, as ablative materials for uses in space applications. Table I summarizes the residual weight results at the designated temperatures of 300,600 and $900^{\circ} \mathrm{C}$. As indicated by the data in Table I, the nanotubes usually lead to the increase of residual weight. The nanocomposite prepared by in situ polymerization method, typically Carboxylated MWNT-PN, shows a higher residual weight than that prepared by meltmixing method. 




Figure 6. TGA of crosslinked phenolic resin (a) and nanocomposites of MMN (b), MWNT-PN (c), and Carboxylated MWNT-PN (d).

Table I. Residual weight of crosslinked phenolic resin and nanocomposites at the designated temperatures

\begin{tabular}{lccc}
\hline \multirow{2}{*}{ Materials } & \multicolumn{3}{c}{ Residual weight/\% } \\
\cline { 2 - 4 } & $300^{\circ} \mathrm{C}$ & $600^{\circ} \mathrm{C}$ & $900^{\circ} \mathrm{C}$ \\
\hline Phenolic resin & 94.0 & 59.6 & 50.4 \\
MMN & 94.3 & 59.7 & 50.9 \\
MWNT-PN & 94.3 & 60.1 & 51.5 \\
Carboxylated MWNT-PN & 94.7 & 62.7 & 53.4 \\
\hline
\end{tabular}

The increased thermostability can be attributed to the ability of nanotubes acting as excellent conductors to disseminate the heat from the surroundings and avoid the formation of hot spots. In respect of this effect, it is critical for nanotubes to disperse well in and adhere strongly to the resin matrix. This has been definitely annotated by Carboxylated MWNT-PN having the highest residual weight (Figure $4 \mathrm{~d}$ and Table I). Moreover, considering a low nanotube load of $\sim 1.0 \mathrm{wt} \%$, it is reasonable to presume that a higher load of well-dispersed nanotubes may provide the nanocomposite with more improvement of thermostability.

Glass transition temperature $\left(T_{\mathrm{g}}\right)$ was measured using DSC. The glass transition of crosslinked phenolic resin was observed at $177^{\circ} \mathrm{C}$, while the $T_{\mathrm{g}} \mathrm{s}$ of nanocomposites were measured to be 179,182 , and $182^{\circ} \mathrm{C}$ for MMN, MWNT-PN, and Carboxylated MWNT-PN, respectively. This slight increase of $T_{\mathrm{g}}$ is expected because the nanotube content is very low.

\section{CONCLUSIONS}

In summary, phenolic resin-MWNT nanocomposites with nanotube well-dispersed in and strongly adhered to phenolic resin have been prepared through a simple but effective in situ polymeriziation method. While carboxylated MWNTs are selected as fillers, their higher dispersion quality and more strong interfacial adhesion to phenolic resin lead to the nanocomposite with more improved thermostability. For melt-mixing method, however, in order to obtain a nanocomposite with the similar performances more mixing energy should be deposited on the melt mixture. Therefore, it is practicable to prepare high performance phenolic resin-MWNT nanocomposites by adoption of pertinent preparation method and moderately functionalized nanotubes. Considering that only a low nanotube load of $\sim 1.0 \mathrm{wt} \%$ was concerned in this work, the nanocomposites with higher performances could be highly expected while more nanotubes are appropriately loaded. Such work is under way in this lab.

Acknowledgment. The financial supports from NSF of China (No. 20704024), NSF of Shandong province (No. Q2007F08), SRF for ROCS (State Education Ministry), and Doctoral Foundation of QUST are gratefully acknowledged.

Received: May 19, 2008

Accepted: July 28, 2008

Published: September 11, 2008

\section{REFERENCES}

1. J. N. Coleman, U. Khan, and Y. K. Gun'ko, Adv. Mater., 18, 689 (2006).

2. P. Liu, Eur. Polym. J., 41, 2693 (2005).

3. P. J. F. Harris, Int. Mater. Rev., 49, 31 (2004).

4. O. Breuer and U. Sundararaj, Polym. Compos., 25, 630 (2004).

5. R. H. Baughman, A. A. Zakhidov, and W. A. de Heer, Science, 297, 787 (2002).

6. E. T. Thostenson, Z. F. Ren, and T. W. Chou, Compos. Sci. Technol., 61, 1899 (2001).

7. P. Calvert, Nature, 399, 210 (1999).

8. A. A. Mamedov, N. A. Kotov, M. Prato, D. M. Guldi, J. P. Wicksted, and A. Hirsch, Nat. Mater., 1, 190 (2002). 
9. P. C. P. Watts, W. K. Hsu, G. Z. Chen, D. J. Fray, H. W. Kroto, and D. R. M. Walton, J. Mater. Chem., 11, 2482 (2001).

10. Y. Lin, M. J. Meziani, and Y. P. Sun, J. Mater. Chem., 17, 1143 (2007).

11. D. Tasis, N. Tagmagtarchis, A. Bianco, and M. Prato, Chem. Rev., 106, 1105 (2006).

12. S. Banerjee, T. Hemraj-Benny, and S. S. Wong, Adv. Mater., 17, 17 (2005).

13. D. Tasis, N. Tagmatarchis, V. Georgakilas, and M. Prato, Chem. Eur. J., 9, 4000 (2003).

14. A. Hirsch, Angew. Chem., Int. Ed., 41, 1853 (2002).

15. J. L. Bahr and J. M. Tour, J. Mater. Chem., 12, 1952 (2002).

16. H. J. Barraza, F. Pompeo, E. A. O'Rear, and D. E. Resasco, Nano Lett., 2, 797 (2002).

17. F. M. Du, J. E. Fischer, and K. I. Winey, J. Polym. Sci., Part B: Polym. Phys., 41, 3333 (2003).

18. M. N. Nadagouda and R. S. Varma, Macromol. Rapid Commun., 28, 842 (2007).

19. S. Bredeau, L. Boggioni, F. Bertini, I. Tritto, F. Monteverde, M. Alexandre, and P. Dubois, Macromol. Rapid Commun., 28, 822 (2007).

20. L. Y. Li, C. Y. Li, C. Y. Ni, L. X. Rong, and B. Hsiao, Polymer, 48, 3452 (2007).
21. D. Crespy, M. Bozonnet, and M. Meier, Angew. Chem., Int. Ed., 47, 3322 (2008).

22. T. Kimura, Y. Nakamoto, and G. Konishi, Polym. J., 38, 606 (2006).

23. B. S. Kaith and Susheel Kalia, Polym. J., 39, 1319 (2007).

24. A. Knop and W. Scheib, "Chemistry and Application of Phenolic Resins.” Springer-verlag, Heidelberg, 1979.

25. Q. Chen, R. W. Xu, and D. S. Yu, Polymer, 47, 7711 (2006).

26. M. K. Yeh, N. H. Tai, and J. H. Liu, Carbon, 44, 1 (2006).

27. A. Igarashi, T. Terasawa, M. Kanie, T. Yamanobe, and T. Komoto, Polym. J., 37, 522 (2005).

28. N. H. Tai, M. K. Yeh, and J. H. Liu, Carbon, 42, 2774 (2004).

29. A. Funck and W. Kaminsky, Compos. Sci. Technol., 67, 906 (2007).

30. G. Q. Guo, D. Yang, C. C. Wang, and S. Yang, Macromolecules, 39 9035 (2006).

31. A. Eitan, K. Jiang, D. Dukes, R. Andrews, and L. S. Schadler, Chem. Mater., 15, 3198 (2003).

32. J. Chen, M. A. Hamon, H. Hu, Y. S. Chen, A. M. Rao, P. C. Eklund, and R. C. Haddon, Science, 282, 95 (1998).

33. R. Verdejo, S. Lamoriniere, B. Cottam, A. Bismarckb, and M. Shaffer, Chem. Commun., 513 (2007).

34. M. S. Dresselhaus and P. C. Eklund, Adv. Phys., 49, 705 (2000).

35. Y. H. Yan, J. Cui, M. B. Chan-Park, X. Wang, and Q. Y. Wu, Nanotechnology, 18, 115712 (2007). 